\title{
Granny shows the way: Results from implementing an alternative fire-lighting method in Orange Farm
}

\author{
M Wentzel \\ PhD student, Institute for Technological Innovation, University of Pretoria
}

\begin{abstract}
High levels of air pollution caused by domestic coal burning create human health problems and unwarranted economic loss. The associated health cost is estimated at R1.2 billion per annum. The Basa Njengo Magogo (BNM) alternative fire lighting method represents the highest impact on health from a benefit-cost and employment point of view since the method can potentially reduce ambient air pollution caused by the use of household coal in a relatively short period, by approximately 40-50\%. In a pilot study funded by the Department of Minerals and Energy (DME), the method was demonstrated to 16000 households through a series of direct demonstrations in Orange Farm. The study found that $99 \%$ of households who attended a demonstration used the BNM method and continued to use it after a month, households saved on average 25 kilograms of coal, translating in a R26 saving per month. A wide scale implementation of the BNM method holds the potential not only to reduce air pollution but also to result in coal and monetary savings for low-income households.
\end{abstract}

Keywords: Orange Farm, Basa Njengo Magogo fire lighting method, air pollution, coal, firewood

\section{Introduction}

Approximately 2.5 billion people globally rely on coal and biomass in various forms for cooking and heating purposes, and are exposed on a daily basis to emissions from these fuels (Ballard-Tremeer, 1997). In South Africa, an estimated 18 million people live in approximately 3 million dwellings of an informal nature, relying on polluting fuels to fulfil their daily energy needs. However, it is not only households in informal settlements that are affected by air pollution from dirty fuels. Low to medium income households in formal areas, despite having access to electricity, are still using cheaper fuels such as coal and paraffin to provide cooking and space heating energy - electricity is largely being used for lighting and entertainment purposes and occasional cooking. Especially in cold winter climates such as the Gauteng Highveld area, areas of Mpumalanga and the Free State, households use coal as an energy source because of its dual and even triple functionality - it provides energy for cooking, water heating and space heating in one, using only one appliance, the family coal stove. Lastly, all households in areas adjacent or close to coal burning areas suffer from the effects or air pollution since everybody has to breath the air out there, even if you live in an affluent suburb.

South Africa's industrial and power generation sectors are responsible for some air pollution, but studies conducted in Gauteng (Scorgie et. al, 2003) found that household coal burning was the largest contributor to air pollution in the area - electricity generation contributed $5 \%$, industries and commercial organisations contributed $30 \%$ and domestic coal burning contributed $65 \%$. A similar study (Matthee, 2004) found source contributions to quantifiable particulate emissions in the city of Johannesburg to be $48 \%$ attributable to domestic coal burning, $22 \%$ to scheduled processes, $20 \%$ vehicle-tailpipe emissions and $10 \%$ to tailings impoundments. Communities are aware of the effects of coal use and the Orange Farm respondents indicated that they experience smoke as a problem in the area, as illustrated in Figure 1.

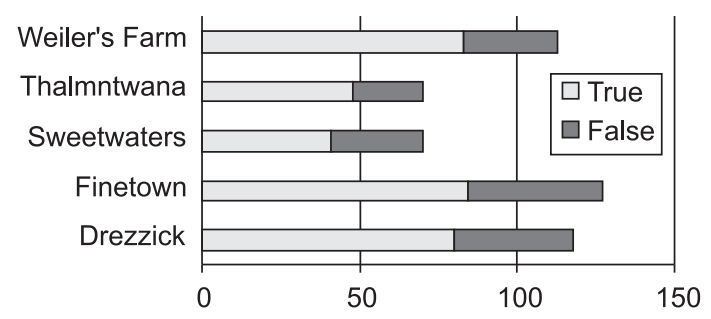

Figure 1: Respondents experiencing smoke as a problem per area

Source PDC, 2005. BNM Final Report 
The worst incidents of poor air quality in South Africa occur with the burning of wood, dung or coal (Terblanche, et al., 1992). This situation proves to become particularly problematic when these fuels are used within poorly ventilated households, especially in informal settlements and rural villages. According to Scorgie et al (2003), approximately 2000 children die annually as a result of respiratory infections caused by air pollution. It is considered the sixth largest killer of children under four in South Africa, and it is estimated that illnesses related to air pollution cost the South African government in the order of R1. 2 billion per annum (Trade and Industry Chamber, 2004).

\section{Background}

This Basa Njengo Magogo (BNM) method was first introduced by the Nova Institute, to the eMhalenhle community near Secunda (van Niekerk and Swanepoel, 1999). The BNM method was named after an elderly lady, Granny Mashinini. (Translated, Basa Njengo Magogo means, 'to make fire like Granny' in reference to Granny Mashinini in eMhalenhle who perfected the top-down fire lighting method.) She represented one of ten households that Nova demonstrated the old 'Scotch-fire' lighting method to. Nine of the households reported that the method did not work, but Granny Mashinini reported that she got the fire to burn after adding a handful of coal on top of the burning wood in the brazier. The addition of the coals added on top provided enough energy to ignite the coal at the bottom. How to light a BNM fire is illustrated in Figure 2.

The BNM method is an attractive intervention to address air pollution caused by domestic coal burning because of the relative low cost associated with its implementation. The Trade and Industry Chamber (2004) concluded that BNM represented the highest impact on health from a benefit-cost and employment point of view. Furthermore, households do not incur any expenses when they switch to the fire lighting method - they don't have to buy special fuel or equipment to be able to use the method - which makes it easy and attractive for households to implement the fire lighting method. The benefits associated with the method were summarised by van Niekerk and Swanepoel (1999):

- Environmental - this method can potentially reduce ambient air pollution caused by the use of household coal in a relatively short period, by approximately 40-50\%;

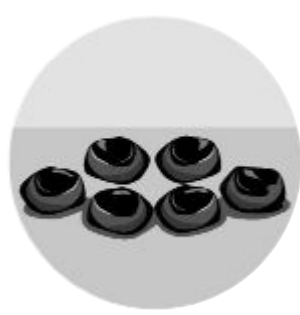

Step 1: Pour a little less coal than you would normally use in your stove or imbawula.

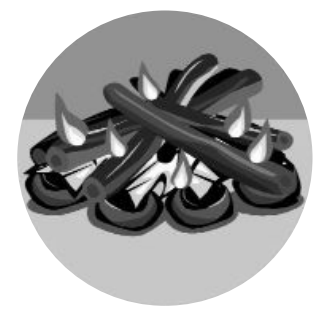

Step 4: Light the fire and wait for the wood to burn well.

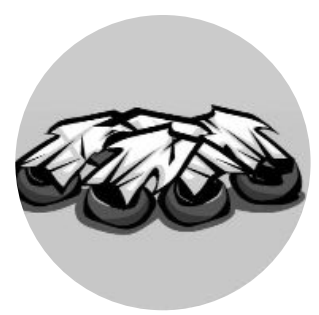

Step 2: Put the paper on top of the coal - about 3 to 4 sheets of newspaper will be enough

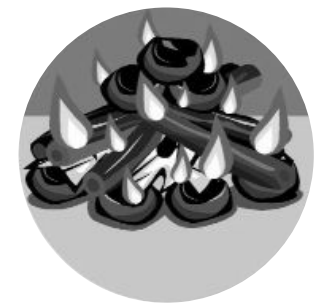

Step 5: Add one to two handfulls of coal on top of the wood.
What are most commonly made mistakes when using the method or trying to use the method?

- Using too little wood - your fire will not be hot enough to light the coal that you place on top;

- Too little coal on top - your fire will die or not ignite well enough to also light the bottom coal;

- Too much coal on top - This is a common mistake which will make your fire just as smoky as the conventional method. Only add one to two handfuls of coal at the top the amount depends on the size of your stove/mbawula;

- If your fire smokes for more than 5 minutes, you have not made a correct BNM fire and you probably added too much coal on to of the fire. Remove some of the extra coals from the top of the fire.

\section{Figure 2: How to make a Basa Njengo Magogo fire}


- Cost element - with conservative estimates indicating that it would cost between R25 million and R50 million to implement this method in one million households;

- Financial benefits - savings in the health costs carried by Government, associated with air pollution. The potential savings to households were calculated at approximately R150 million as a result of the decrease in the amount of coal used due to this method.

The BNM method has a direct impact on the way in which coal combusts in the lightning process, resulting in a significant reduction in visible smoke and particulate matter (see Figure 3). The method is based on the principle of putting the coal first in the brazier, followed by newspaper, and then wood on top. The paper and wood is lighted, and when it is burning well, two handfuls of coal are added on top. The main idea is that the fire burns from the top-down; affecting the combustion process in such a way that the smoke emitted from the burning process is reduced by up to $50 \%$, whilst increasing the efficiency while the coal is burning. The advantage of the introduction of the new method is that it can be used in either braziers or coal stoves, or even in open fires (Figure 4) and does not threaten the position of the coal merchants, as it does not attempt to substitute coal with another energy source. The BNM method can be used for lighting any coal fire and works in braziers (mbawualas), coal stoves and open coal fires as used for funerals, weddings or community feasts. During the demonstration programme, braziers were used in street demonstrations because they are easier to carry around.

Nova (van Niekerk and Swanepoel, 1999) indicated that before the introduction of the BNM method, for the period May to August 2001, the air quality monitoring of PM2.5 particulate concentration was 306.25 micrograms per cubic metre. Measurements of above 600 and indoor measurements and 1000 micrograms were recorded per cubic metre. PM2.5 particulates are known to contain most of the potentially toxic deposit in the lungs (Annegarn and Sithole, 1999). However, after introducing the BNM method, a decrease of 211.8 micrograms per cubic metre was recorded.

Having established various facts such as household take-up rates, coal savings and air pollution reduction potential regarding the BNM method in eMhalenhle, the Department of Minerals and Energy (DME) contracted Palmer Development Consulting (PDC), in cooperation with Dikepolana Consulting, O'Brian Advertising and MKX Admin Services to implement a large-scale dissemination campaign of the method in the Orange Farm area of Gauteng. The project had to verify the results of the eMhalenhle study and based on the experience

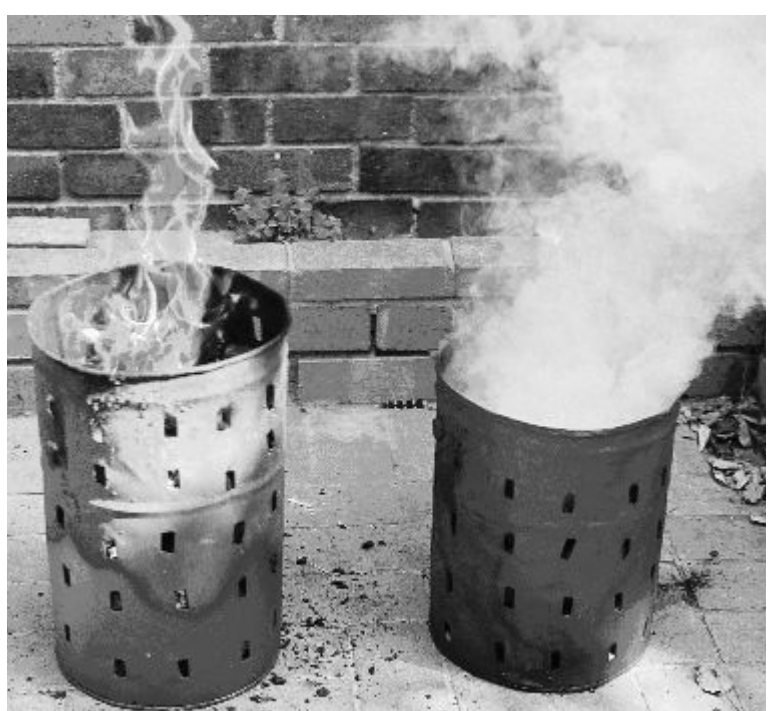

Figure 3: Illustrating the visible reduction of smoke when using BNM

Photograph: Marlett Wentzel

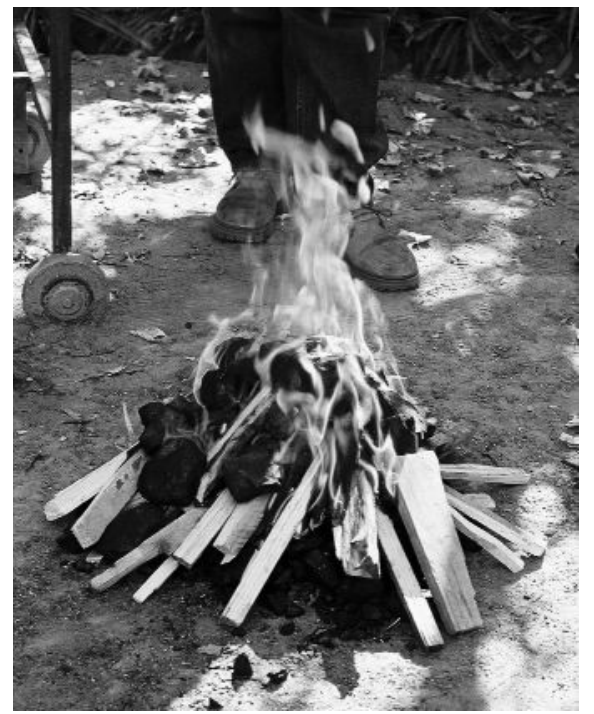

Figure 4: BNM can also successfully be employed in open fires

Photograph: Marlett Wentzel

with a large-scale project implementation, make recommendations for a national rollout of a BNM demonstration programme in coal burning areas of South Africa.

\section{Methodology and dissemination method}

O'Brian Advertising developed the marketing and awareness raising methodology, together with inputs from the project team. The objectives of the marketing process were to create awareness for the new method, inform, demonstrate and campaign for the adoption of the new method. It was aimed to structure the tone of the message to be factual and straight-to-the-point, and to use an icon, in this case Granny Mashinini herself (see below). It was 
also decided that a graphical and easy to follow depiction of the method had to be incorporated into graphic material produced by the project. Awareness raising and demonstrations had to go hand-in-hand, and it was decided to hand out incentives like T-shirts and caps at demonstrations. The demonstration of the method coincided with awareness raising about pollution and its relationship to health, savings on coal and safety.

An energy baseline study was conducted to inform the implementation planning. Households, schools, clinics and coal yards were interviewed and 31 field workers or demonstrators from the Orange Farm were identified and trained. Most of the fieldworkers had been volunteering as health workers and HIV/AIDS support workers at local clinics in the area. The project focussed on employing female fieldworkers (26 out of 31 fieldworkers were female), as Orange Farm is notorious for its high crime level, and especially women in households being interviewed may have felt safer being interviewed by a woman. The activities of cooking, fuel purchase and fire lightning are also often the responsibility of women, although men carrying out these activities headed some of households that were interviewed.

A method had to be devised through which households could be visited and their use of the demonstrated BNM method monitored. The names of people attending each demonstration were recorded on a demonstration attendance list, but only one representative per household was counted towards the project target of 16000 households. Every household on the list was visited the following day where a daily follow-up questionnaire was completed. Ten households were selected from the daily follow-up list and re-visited one week later, with once again a questionnaire being filled out. The same follow-up procedure applied to a month later. During phase two, the daily follow-up was eliminated and only 10 households per demonstration from the demonstration attendance register was visited on a weekly and monthly basis. The reason for this was that the acceptance rate of households trying the method directly after the demonstration was proven sufficiently in the first phase.

Demonstrations were conducted by a group of 30 fieldworkers, working in 10 teams of 3 people each. Each team had to conduct at least 3 demonstrations per day. A drama group was formed amongst the fieldworkers who devised a short skit, which was used at schools and larger gatherings. Loud hailers and banners were used to catch people's attention and to convince them to attend demonstrations. In the first phase of the project, 115 demonstrations took place to reach the initial target of 1000 households, and a total of 1422 individuals were reached. During the second phase, demonstrations were also held at clinics, coal yards, shopping centres, on street corners, at a local train station and at sport stadiums. During this phase, 14 258 people were reached in the 192 demonstrations that took place. In total 15707 people were directly reached through the 307 demonstrations held. In addition, households were also asked to identify other individuals and households that were told about the method or to whom the method was illustrated. When these households (3 719) are also taken into account, the project reached at least 19 425 people.

\section{Project impacts \\ 4.1 Take-up rates}

In the first follow up session one or two days after the demonstration, already $84 \%$ of households started using the method, and most of them reported that they would continue to use the method in future. The $16 \%$ of households indicating that they would not use it in future actually don't use coal or

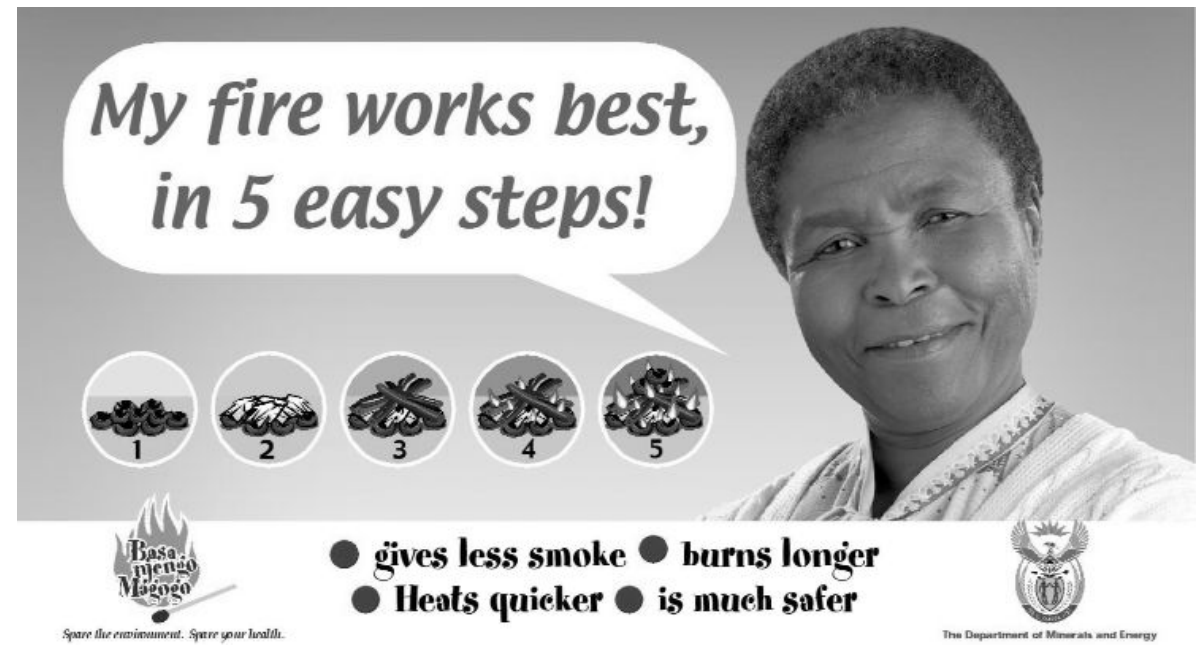

Figure 5: Banner showing Granny Mashinini as campaign icon and graphic illustration of BNM method 
did not have coal in the house to try the method. A week after the demonstration, $96 \%$ of the households were using the method every day, thus there was an increase from $84 \%$ to $95 \%$. The percentage of households reporting that they are still using the method after a month, increased to $99 \%$, of which $1.7 \%$ of those households using the method did not use coal before. The suggestion here is that coal use actually increased overall due to the fact that a new, cleaner alternative lightning method became available and people felt safer to use the method.

\subsection{Coal and monetary savings}

Coal savings and associated monetary savings arise from the fact that with the BNM method, coal is burned more efficiently. Smoke is unburned carbon or unburned energy and with the conventional method, the energy in the smoke is lost, while with the BNM method the smoke is burned and available as useful energy. Secondly, when the method is used in a coal stove, the fire is made at the top of the stove, providing instant heat for cooking on the stovetop. Households therefore, do not have to wait 20 minutes for the stove to warm up before cooking can start. Respondents reported saving coal and that their fire last longer: During the daily follow-up, $14 \%$ of respondents reported that they liked the method as it saves coal, and $31.6 \%$ reported that the fire lasts longer. The weekly follow-up reported $11.4 \%$ of respondents liking the method because it saves coal (meaning a $2.6 \%$ decrease), and $40.5 \%$ of respondents felt that the fire lasts longer.

The actual amount of coal saved varied from household to household but the majority of households indicated coal savings of half a bag per week (25 kilograms). The various levels of coal savings

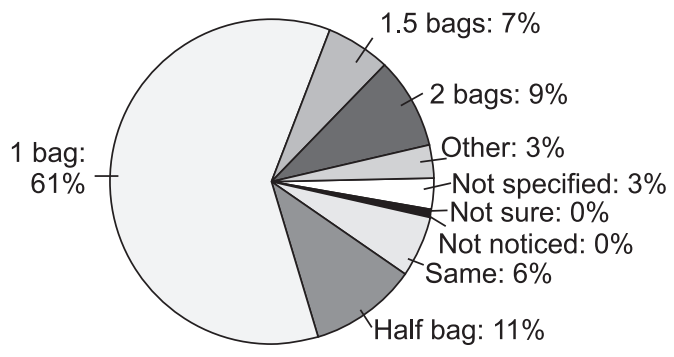

reported is illustrated in Figure 6.

Figure 6: Reported coal savings after a month of using BNM

Source BNM Final Report, 2003

Most of the households (73\%) used to make a fire twice a day with the conventional fire lighting method, but $92 \%$ of those households only needed to make a fire once per day with the BNM method. Coal savings has a direct impact on the household budget, and on average, households reported spending R104 per month on coal for 4 bags of coal in the 5 study areas. Should the households save one bag per month by using the BNM method, they would at least save R26 per month.

There are also other indirect monetary savings such as expenses associated with health and education, which could not be quantified through the study quantified.

\subsection{Reduction in air-pollution}

Households, scholars and schools were interviewed to obtain their perception on air pollution, and all 12 schools interviewed reported air pollution as a problem in their area. Of the scholars interviewed, $59 \%$ reported smoke being a problem in their households. These scholars might be so accustomed to smoke in their households that it does not bother them that much, but $84 \%$ of them definitely perceived it as a problem in their community.

After the households had time to try and test the method, they were asked in both the weekly and monthly follow up whether they noticed less smoke when lighting a fire and if they noticed less smoke in their community. The weekly follow up indicated a $76 \%$ positive feeling towards less smoke when lighting the fire, and the same figures apply to the monthly follow-up. In the weekly follow-up, $55 \%$ of households noticed less smoke in the streets, and during the monthly follow-up, $67 \%$ of them noticed less smoke in the streets.

\section{Cost of implementation}

The total number of demonstrations held during the course of the project amounted to 307, at an average of 6 demonstrations held per day. A total of 15 707 households were reached directly, and if the spill-over is taken into account, another 3718 households were reached, totalling 19425 households. The average direct cost per demonstration amounted to R853.01 but when the cost of the research and project management component was also taken into account, the cost per demonstration was R2451.36.

The cost per household reached amounted to R16.28 (expenses only) and R37.15 (with professional fees taken into account). For future implementation programmes, the actual cost will lie somewhere in-between the two above-mentioned amounts.

\section{Conclusions and recommendations}

The potential impacts of coal and monetary savings were verified in the project area and reported improvements in smoke reduction and health documented. The project demonstrated the implementation of a demonstration and awareness programme and reached the required number of households.

The conclusions drawn were:

- The implementation of the BNM method can 
reduce air pollution, affect coal and monetary savings and improve the health of communities dependent on coal as an energy source for space heating and cooking;

- An awareness raising and information dissemination campaign would be strongly dependent on demonstrations. Demonstrations have a double impact - it teaches people how to make a $\mathrm{BNM}$ fire and it shows the difference between a conventional and a BNM fire. As the difference in smoke release is quite dramatic, it is a very effective way to convince people of the benefits of the method;

- Although implementing a demonstration and awareness raising programme is logistically challenging and resource intensive, the project demonstrated that it is achievable. Furthermore, the cost of R38 to reach a household as demonstrated in the project may be lowered to as much as R17 per household, with greater efficiencies and a smaller research component per project.

\section{References}

Desirability, Final Report Annegarn H.J. and Sithole J.S. 1999. Soweto Air Monitoring - SAM Project, Quarterly Report for Soweto (September - November 1999) and Synopsis for March to August 1999. Report DEAT No. AER20.001 Q SAM

Ballard-Tremeer, G. 1997. Emissions of rural wood-burning cooking devices. University of the Witwatersrand. Thesis submitted to the Faculty of Engineering in fulfilment of the requirements for the degree Doctor of Philosophy.

Mathee, A. 2004. Indoor Air Pollution in Developing Countries. Recommendations for Research Commentary on the Paper by Professor Kirk R Smith. South African Medical Research Council: Pretoria.

Palmer Development Consulting. 2005. Basa Njengo Magogo Pilot Study: Orange Farm. Final Project Report. Department of Minerals and Energy: Pretoria.

Scorgie, Y, Burger, L and Annergan, H. 2003. Vaal Triangle source apportionment study. Paper delivered the National Association for Clean Air Conference, October 2003.

Terblanche, P; Nel, C.M and Opperman, L. 1992. Health and safety aspects of domestic fuels. Department of Minerals and Energy: Pretoria. Final Report NE14/6/30

Trade and Industry Chamber. 2004. Fund for Research into Industrial Development Growth and Equity (FRIDGE). Study to examine the potential socio-economic impact of measures to reduce air pollution from combustion. Final Report.

Van Niekerk A.S. and Swanepoel. P.A. (1999). Sasol Synthetic Fuels: eMbalenhle Air Quality Project, Phase Two, Indoor Air Quality and, Report No. 98/14, 29 January 1999. 